\title{
82. Arbeitstagung des ALTS
}

Auf Grundlage von $\S 8$ Nr. 4 der Geschäftsordnung veröffentlicht der Arbeitskreis der auf dem Gebiet der Lebensmittelhygiene und der Lebensmittel tierischer Herkunft tätigen Sachverständigen (ALTS) die auf der 82. Arbeitstagung vom 05. und 06. Dezember 2018 in Erlangen gefassten Beschlüsse.

\section{TOP 08 Anwendbarkeit des Artikels 25 der VO (EU) Nr. 1169/2011 auf vorverpacktes, rohes Fleisch}

\subsection{Sachverhalt/Frage}

Kann bei vorverpacktem, rohem Fleisch und der Angabe des Verbrauchsdatums als ,ungeöffnet ... zu verbrauchen bis..." eine Angabe zur angemessenen Aufbewahrung oder Verwendung des Lebensmittels nach Öffnen der Verpackung i. S. von Art. 25 Abs. 2 der VO (EU) Nr. 1169/2011 gefordert werden?

\subsection{Beschluss}

Die Angabe, dass das Verbrauchsdatum bei vorverpacktem, rohem Fleisch nur bei „ungeöffneter“ Verpackung gültig ist, bedingt keine Angabe zur angemessenen Aufbewahrung oder Verwendung i. S. von Art. 25 Abs. 2 der VO (EU) Nr. 1169/2011.

\section{TOP 14 Kennzeichnung von Laktase im Zutatenverzeichnis von laktosefreier Milch}

\subsection{Sachverhalt/Frage}

Für Lebensmittel besteht nach Art. $9 \mathrm{~b}$ in Verbindung mit Art. 18 Abs. 1 der VO (EU) Nr. 1169/2011 die
Verpflichtung zur Angabe eines Zutatenverzeichnisses, das sämtliche Zutaten aufführt. Nach Art. 20 der VO (EU) Nr. 1169/2011 sind bestimmte Stoffe von der Verpflichtung zur Angabe im Zutatenverzeichnis befreit.

Fällt Laktase, die bei der Herstellung von Konsummilch verwendet wird, unter einen der Tatbestände des Art. 20 VO (EU) Nr. 1169/2011 zur Befreiung von der Angabe im Zutatenverzeichnis?

\subsection{Beschluss}

Bei Laktase handelt es sich um ein Lebensmittelenzym. Für die Einordnung dieses Lebensmittelenzyms als Zutat, Zusatzstoff oder Verarbeitungshilfsstoff ist nach dem Guidance Document on Criteria for Categorisation of Food Enzymes der Kommission vom 24. Februar 2014 die Art und das Ausmaß des Effekts auf das vermarktete Lebensmittel entscheidend. Die Reduzierung des Laktosegehaltes durch die Laktase („technological effect“) im Enderzeugnis ist essentiell, entscheidend und evident. Ohne Laktase wird bei diesen Erzeugnissen keine Laktosereduktion bzw. Laktosefreiheit erreicht.

In diesem Zusammenhang ist es unerheblich, ob die Laktase in dem Lebensmittel noch eine technologische bzw. enzymatische Wirkung ausübt oder nicht.

Somit kann Laktase nicht als Verarbeitungshilfsstoff eingeordnet werden und fällt nicht unter den Tatbestand nach Art. 20 Buchst. b) Unterabsatz ii) der VO (EU) Nr. 1169/2011 zur Befreiung von der Angabe im Zutatenverzeichnis. Laktase ist nach Art. 18 der VO (EU) Nr. 1169/2011 im Zutatenverzeichnis anzugeben.

Der ALS trägt diesen Beschluss mit.

Publisher's Note Springer Nature remains neutral with regard to jurisdictional claims in published maps and institutional affiliations. 